\title{
INTRODUÇÃO AO FÓRUM ESPECIAL TEMÁtICO SOBRE A CONSTRUÇÃO DO PERCURSO NA VIDA LABORAL E SUAS MÚLTIPLAS DIMENSÕES
}

A discussão sobre a construção do percurso na vida laboral e suas múltiplas influências passa necessariamente pela discussão da centralidade do trabalho.

A centralidade do trabalho tem sido abordada em diferentes perspectivas. Sérgio Lessa (I997), no artigo "Centralidade do trabalho: qual centralidade?", faz uma reflexão em que contrapõe as perspectivas de Marx, Lukács e Habermas sobre os vários tipos de centralidade: centralidade ontológica do trabalho, do trabalho, política dos trabalhadores e do trabalho na vida cotidiana. Para tratar da centralidade ontológica do trabalho, Lessa (1997) compara as abordagens de Marx e Lukács com a de Habermas. Nas duas primeiras, a centralidade do trabalho é concebida como ontológica, pois, segundo os filósofos, é mediante o trabalho que o homem transforma a natureza com o propósito de gerar meios para a própria subsistência e afastar-se do poder determinante da natureza. É pelo trabalho que o homem concebe a si mesmo e se transforma ao transformar a natureza. Por sua vez, Habermas contrapõe-se à abordagem ontológica e defende a fenomenológica com a teoria do agir comunicativo e a concepção de mundo da vida, oferecendo uma teoria que concebe o homem como ser subjetivo e social em sua totalidade, não fazendo sentido a concepção ontológica da centralidade do trabalho.

A centralidade do trabalho como centralidade política do trabalhador é outro aspecto discutido por Lessa (1997). Para o autor, considerar, no âmbito do capitalismo, a centralidade ontológica ou fenomenológica do trabalho não implica centralidade política do trabalhador nem centralidade cotidiana do trabalho.

De acordo com Cardoso (20II), alguns autores defendem que a centralidade do trabalho, como uma categoria sociológica, deixa de ter sentido no mundo capitalista como uma categoria fundante das relações sociais. No entanto, conforme o autor, as críticas carecem de consistência. Toni (2003, p. 262) já apontava que, 
paralelamente à corrente que defendia o fim da centralidade do trabalho, outra surgia como alternativa que visava "analisar as transformações no trabalho sob o ângulo de suas implicações sociais, isto é, de seus efeitos sobre as relações de trabalho e sobre a organização social", uma vez que a sociedade capitalista se organiza em torno do trabalho assalariado. Nessa perspectiva, a precariedade do trabalho é destacada como característica do sistema capitalista.

Dejours (2004), sob o enfoque da psicologia clínica, apresenta outra visão sobre o trabalho. Não são as relações sociais, como relações político-econômicas, que assumem o centro das discussões, mas o ato de trabalhar e a subjetividade envolvida no processo. Para Dejours (2004, p. 28),

[...] o trabalho é aquilo que implica, do ponto de vista humano, o fato de trabalhar: gestos, saber-fazer, um engajamento do corpo, a mobilização da inteligência, a capacidade de refletir, de interpretar e de reagir às situações; é o poder de sentir, de pensar e de inventar, etc. Em outros termos, para o clínico, o trabalho não é em primeira instância a relação salarial ou o emprego; é o "trabalhar", isto é, um certo modo de engajamento da personalidade para responder a uma tarefa delimitada por pressões (materiais e sociais).

Segundo o psicanalista francês, o trabalho implica o ato de trabalhar, e este resulta em emoção, subjetividade e ação. Quanto à subjetividade, afirma Dejours (2004, p. 30):

O trabalho sempre coloca à prova a subjetividade, da qual esta última sai acrescentada, enaltecida, ou ao contrário, diminuída, mortificada. Trabalhar constitui, para a subjetividade, uma provação que a transforma. Trabalhar não é somente produzir; é, também, transformar a si mesmo e, no melhor dos casos, é uma ocasião oferecida à subjetividade para se testar, até mesmo para se realizar.

No Fórum "A Construção do Percurso na Vida Laboral e suas Múltiplas Dimensões”, embora as dimensões da subjetividade e ação não estejam exatamente postas, não deixam de estar implícitas e, por vezes, até explícitas, como é caso do artigo "Sentidos do trabalho apreendidos por meio de fatos marcantes na trajetória de mulheres prostitutas, de Késia Aparecida Teixeira Silva e Mônica Carvalho Alves Cappelle. Essa pesquisa teve por objetivo apreender os sentidos subjetivos produzidos por mulheres que atuam na prostituição, em boates do interior de Minas Gerais. O trabalho dessas mulheres, que, na pesquisa de Silva e Cappelle, ganha visibilidade acadêmica é corajoso. Trata-se de um trabalho 
socialmente proscrito mas paradoxalmente permitido que mostra não apenas os sentidos do trabalho atribuídos pelas mulheres entrevistadas, mas também o abandono perverso e permitido a que são remetidas, o que estimula a nossa reflexão. Nesse artigo, o percurso no trabalho mostra-se afetado por uma dimensão social que se refere à proscrição/prescrição social do tipo de trabalho realizado.

$\mathrm{Na}$ outra ponta - do trabalho socialmente aceito, ou melhor, do comportamento no trabalho socialmente aceito -, temos o artigo de Germano Glufke Reis e Marcia Carvalho de Azevedo: "Relações entre autenticidade e cultura organizacional: o agir autêntico no ambiente organizacional". Esse estudo mostra que, embora a autenticidade seja um valor socialmente aceito e até desejável, o comportamento autêntico dentro das organizações sofre a influência da cultura organizacional. De acordo com os autores, as culturas organizacionais do tipo clã e inovadoras estão positivamente relacionadas à expressão da autenticidade e do comportamento autêntico no trabalho, o que já não ocorre, nos limites da pesquisa, em organizações primordialmente orientadas para hierarquia e resultados. Lembrando Dejours (2004), podemos pensar na situação paradoxal em que podem encontrar-se indivíduos que intrassubjetivamente sejam orientados para agir com autenticidade no ambiente de trabalho, entretanto o agir intersubjetivo não lhes permite vivenciá-la, ou melhor, restringe essa vivência por conta da cultura organizacional em que estão inseridos. Temos aqui uma outra dimensão do percurso no trabalho: a proscrição/prescrição do comportamento inserida na cultura organizacional. A autenticidade é um comportamento socialmente desejável, porém as organizações, que, por sua vez, são socialmente inscritas, podem ou não aceitar ou proscrever esse comportamento. Os resultados da pesquisa nos indicam que o percurso no trabalho tem uma outra dimensão: a da proscrição ou aceitação/estímulo a um comportamento socialmente considerado desejável.

Paula Rodrigues Agapito, Angelo Polizzi Filho e Mirlene Maria Matias Siqueira, autores de "Bem-estar no trabalho e percepção de sucesso na carreira como antecedentes de intenção de rotatividade", abordam aspectos relacionados à percepção de sucesso na carreira e bem-estar no trabalho e à intenção dos indivíduos de se manter na empresa ou de sair dela. Nesse artigo, os resultados da pesquisa indicam que a percepção do bem-estar no trabalho exerce mais influência sobre a intenção de saída da organização ou permanência nela do que o sucesso percebido na carreira. Trata-se de outra dimensão do percurso no trabalho. O bem-estar no trabalho tem sido amplamente estudado por diferentes abordagens, haja vista as pesquisas realizadas por Dessen e Paz (20I0) e Paschoal e Tamayo (2008), e já é conhecido como uma dimensão que afeta o percurso dos indivíduos no trabalho.

Outra dimensão do percurso no trabalho trata do trabalho como uma construção individual/coletiva. Thaís Gualda Carneiro Akiyama, Veronica Eberle de 
Almeida, Luciana Godri e Edson Ronaldo Guarido Filho trazem um exemplo de construção coletiva no artigo "Organizações e ambiente legal: a construção do sistema de identificação civil brasileiro”. Nesse estudo, os autores abordam a articulação de diferentes atores sociais - organizacionais, públicos e privados - na construção de uma lei. A construção coletiva do trabalho tem sido abordada em diferentes esferas, como na educação (Ferrari, 20II) e na saúde (Prates, Garcia, \& Moreno, 20I3), porém essa dimensão ainda é pouco explorada. Em estudo realizado por Cavalcante, Oliveira e Cavalcante (2009) com profissionais da saúde mental no Ceará, os participantes revelaram sentir falta de espaço para a construção coletiva do trabalho. De acordo com as autoras, é fundamental que o tema receba maior atenção dos pesquisadores.

Outra dimensão de percurso no trabalho apresentada neste fórum consiste nas práticas de recursos humanos. O artigo "Necessidades de treinamento: uma proposta de avaliação estratégica no contexto de empresas juniores brasileiras", de Elziane Bouzada Dias Campos, Gardênia da Silva Abbad, Andressa Gonzalez Azevedo Pinheiro Soares Macedo e Natália Pimenta Silva, insere-se nessa dimensão ao avaliar necessidades de treinamento e identificar condições de suporte oferecidas para que os empresários juniores possam obter capacitação.

Em suma, neste fórum, foram contempladas cinco dimensões do percurso no trabalho: proscrição/prescrição social do tipo de trabalho realizado, proscrição/prescrição de comportamento no trabalho inserida na cultura organizacional, bem-estar no trabalho/mal-estar, construção coletiva/individual do trabalho e práticas de recursos humanos.

As dimensões proscrição/prescrição social do tipo de trabalho realizado e proscrição/prescrição de comportamento no trabalho inserida na cultura organizacional mostram que o trabalho continua exercendo papel organizador das relações sociais, como já sinalizado por Cardoso (20II). A dimensão bem-estar/mal-estar no trabalho está associada, de forma explícita, à dimensão da subjetividade do trabalhador apontada por Dejours (2004), enquanto a dimensão construção coletiva/individual do trabalho pode ser entendida como uma dimensão política.

Mas afinal o que se entende por "percurso no trabalho"? Tratar-se-ia de trajetória? Trajetória pode ser entendida como o percurso para se ir de um ponto A um ponto B, enquanto percurso é um caminho percorrido no processo de caminhar. "Percurso no trabalho" refere-se ao caminhar pelo processo de trabalhar e de desenhar o percurso. Não se trata especificamente de um percurso linear, mas de um percurso de idas e vindas, de desenhos e redesenhos de caminho, interrupções e "re-retornos", porque cada retorno é um retorno no processo de trabalhar. Tanto o desenho e quanto o redesenho de percurso vão sendo construídos de acordo com a vivência das diferentes dimensões que estão imbricadas nesse caminhar. Queremos encorajar os leitores a percorrer os artigos que aqui 
se apresentam e se lançar em novas pesquisas, de modo a construir e ampliar dimensões do percurso no trabalho, com o propósito de aprofundar ainda mais a compreensão do fenômeno do trabalhar.

\section{REFERÊNCIAS}

Cardoso, L. A. (20II). A categoria trabalho no capitalismo contemporâneo. Tempo Social, 23(2), 265-295.

Cavalcante, L. M. S., Oliveira, H. C., \& Cavalcante, S. M. A. (2009). Análise da contribuição de Dejours para o entendimento da relação prazer/sofrimento no trabalho do profissional de saúde mental - estudo de caso em Centro de Atenção Psicossocial em Fortaleza (CE). Encontro da Associação Nacional de Pós-Graduação e Pesquisa em Administração, São Paulo, SP, Brasil, 33.

Dejours, C. (2004). Subjetividade, trabalho e ação. Produção, 14(3), 27-34.

Dessen, M. C., \& Paz, M. G. T. (20ıо, julho-setembro). Bem-estar pessoal nas organizações: o impacto de configurações de poder e características de personalidade. Psicologia: Teoria e Pesquisa, 26(3), 409-4I8.

Ferrari, G. V. (20II, dezembro). A importância do coletivo na construção do projeto político pedagógico da instituição escolar. Perspectiva, 35(132), I59-I70.

Lessa, S. (1997). Centralidade do trabalho: qual centralidade? Revista de Ciências Humanas, 15(22). Paschoal, T., \& Tamayo, A. (2008, abril). Construção e validação da escala de bem-estar no trabalho. Avaliação Psicológica, 7(I), II-22, I53-I64.

Prates, M. M. L., Garcia, V. G., \& Moreno, D. M. F. (2013). Equipe de apoio e a construção coletiva do trabalho em saúde mental junto à estratégia de saúde da família: espaço de discussão e de cuidado. Saúde Social, 22(2), 642-652.

Toni, M. (2003). Visões do trabalho em transformação. Sociologia, ano 5(9), 246-286.

MARIA LUISA MENDES TEIXEIRA

Doutora em Administração de Empresas pela Faculdade de Economia, Administração e Contabilidade da Universidade de São Paulo (USP). Professora adjunta do Programa de Pós-Graduação em Administração de Empresas da Universidade Presbiteriana Mackenzie (PPGA-UPM). Rua da Consolação, 930, Consolação, São Paulo - SP - Brasil - CEP 01302-907 E-mail:malluluisa@gmail.com 